\title{
PENGEMBANGAN MODUL KIMIA PADA MATERI SISTEM PERIODIK UNSUR BERBASIS BUDAYA LITERASI
}

\author{
Tiurlina Siregar \\ Program Studi Magister Pendidikan IPA UNCEN; tiurlina.siregar@yahoo.com
}

\begin{abstract}
This study aims to determine the feasibility of a literacy culture-based chemistry module on the Elements Periodic System (SPU) material and to determine the increase in student learning outcomes. Research Methods Research and Development. The sample of the research was 12 students of the Master of Science Education Study Program, FKIP UNCEN. The results showed that the chemistry module was suitable for use as teaching material and the improvement of student learning outcomes with the $n$-Gain test was obtained an average of 0.81 in the high category.
\end{abstract}

Keywords: Chemistry Module; Unsu Periodic System; Literacy Culture

\begin{abstract}
ABSTRAK
Penelitian ini bertujuan untuk mengetahui kelayakan modul kimia berbasis budaya literasi pada materi Sistem Periodik Unsur' (SPU) dan mengetahui peningkatan hasil belajar mahasiswa. Metode Penelitian Research and Development. Sampel penelitian mahasiswa S2 Prodi Pendidikan IPA FKIP UNCEN dengan jumlah 12 orang. Hasil penelitian menunjukkan bahwa modul kimia layak digunakan sebagai bahan ajar dan peningkatan hasil belajar mahasiswa dengan uji $n$-Gain diperoleh rata-rata 0,81 berkategori tinggi.
\end{abstract}

Kata Kunci : Modul Kimia; Sistem Periodik Unsu; Budaya Literasi.

\section{PENDAHULUAN}

Pasal 32 ayat (1) Undang-Undang Dasar Negara Republik Indonesia Tahun 1945 menyatakan bahwa negara memajukan kebudayaan nasional di tengah peradaban dunia dengan menjamin kebebasan masyarakat dalam memelihara dan mengembangkan nilai-nilai budayanya. Artinya semua pemerintah daerah dan semua stakeholder harus mengambil peran dalam upaya kemajuan kebudayaan daerah berdasarkan kearifan lokalnya. Dalam dunia pendidikan misalnya dalam proses pembelajarannya.
Secara interaktif, inspiratif, menyenangkan, menantang, memotivasi peserta didik untuk berpartisipasi aktif, serta memberikan ruang yang cukup bagi prakarsa, kreativitas, dan kemandirian sesuai dengan bakat proses pembelajaran diselenggarakan, dan perkembangan fisik serta psikologis peserta didik. Untuk itu setiap satuan pendidikan melakukan perencanaan pembelajaran, pelaksanaan proses pembelajaran serta penilaian proses pembelajaran untuk meningkatkan efisiensi dan efektivitas ketercapaian 
kompetensi lulusan (Lampiran

Permendikbud Nomor 22 tahun 2016).

Peranan dan fungsi pendidikan di dalam kehidupan suatu bangsa tidak bisa terlepas dari kehidupan politik, ekonomi, hukum, dan kebudayaan. Perluasan otonomi daerah menyebabkan perubahan kebijakan di dalam dunia pendidikan, dimana daerah memiliki porsi yang lebih besar dalam menentukan kebijakan pendidikan. Sehingga daerah dan sekolah diberi kewenangan untuk menentukan sistem yang akan digunakan dalam melaksanakan proses pembelajaran, dan strategi pembelajaran. Hal ini merupakan peluang bagi daerah untuk mengembangkan budaya literasi dalam kaitannya dengan pembelajaran.

Peraturan Menteri No 23 Tahun 2015 dikeluarkan oleh Kementerian Pendidikan dan Kebudayaan Indonesia. Peraturan Menteri tersebut berisi tentang penumbuhan budi pekerti yang di dalamnya mencakup Gerakan Literasi Sekolah (GLS) dengan mewajibkan peserta didik membaca buku non pelajaran selama 10-15 menit sebelum pembelajaran dimulai. Budaya menulis dan membaca (literasi) pada warga sekolah, baik kepala sekolah, guru dan peserta didik, yang berujung pada kemampuan mamahami informasi secara reflektif, kritis dan analitis, adalah merupakan tujuan menumbuhkan GLS GLS juga bertujuan menciptakan lingkungan sekolah menjadi lingkungan pembelajar sepanjang hayat dengan membudayakan aktivitas membaca dan menulis. Konsep Gerakan Literasi Sekolah (GLS) yang kelihatannya mudah diterapkan, ternyata tidak mudah dalam pengaplikasiannya di sekolah, dalam mengakomodasi penciptaan lingkungan sekolah yang literat disebabkan oleh , setiap sekolah tidak memilki kemampuan yang sama.

Lembaga pendidikan tinggi tenaga kependidikan (LPTK) adalah lembaga yang menghasilkan tenaga pendidik dan tenaga kependidikan.Oleh sebab itu LPTK bertanggung jawab akan pelaksanaan pendidikan yang berkualitas. Tenaga pendidik atau guru yang merupakan produk dari LPTK maka teori-teori belajar dan pembelajaran diperoleh dari bangku perkuliahan. Kemampuan mahasiswa dalam berliterasi merupakan hal yang sangat penting diajarkan. Perkembangan dunia di era globalisasi merupakan permasalahan yang harus diatasi, khususnya di dunia pendidikan karena adanya kesenjangan antara harapan dan kenyataan. Potensi dan kemampuan mahasiswa harus ditingkatkan secara optimal sehingga mahasiswa mampu beradaptasi dengan keadaan dan perubahan yang terjadi serta mampu secara kolaboratif bekerja sama dalam memecahkan masalah kehidupan. Pembentukan mahasiswa untuk dapat 
membangun kapasitas pengetahuannya dengan mengembangkan kemampuan berpikir tingkat tinggi, seperti berpikir kritis, membuat keputusan, dan memecahkan masalah dapat diperoleh melalui pendidikan. Budaya literasi dapat dilaksanakan dalam membiasakan mahsiswa dalam berfikir kritis.

Salah satu mata kuliah wajib di program studi S2 Magister Pendidikan IPA FKIP UNCEN adalah mata kuliah kimia. Pemahaman kimia dimulai dari memperkenalkan Sistim Periodik Unsur (SPU) karena harus menjelaskan 108 unsur dalam SPU. Hal ini akan menyulitkan mahasiswa untuk menghafal dan menjelaskan tiap-tiap unsur masuk pada golongan, periode, nomor atom dan sifatsifat dari unsur-unsur tersebut. Menurut Subiyanto, Tiurlina Siregar (2018) bahwa modul kimia dapat meningkatkan hasil belajar kimia.

Karakteristik ilmu kimia sebagai sikap, proses dan produk perlu diperhatikan dalam penilaian hasil belajar kimia. Selama ini ada kecenderungan sebagian tenaga pendidik kurang memperhatikan karakteristik ilmu kimia dalam pembelajaran dan hasil belajar kimia. Dalam pembelajaran dan penilaian hasil belajar kimia tentunya tidak terlepas dari standar kualifikasi akademik dan kompetensi guru diantaranya adalah kompetensi pedagogik, kompetensi kepribadian, kompetensi profesional dan kompetensi sosial seperti menyelenggarakan perencanaan pembelajaran, melaksanakan pembelajaran, melakukan penilaian proses pembelajaran dan penilaian hasil pembelajaran dengan menumbuhkan pembiasaan karakter dalam membuat perencanaan dan pelaksanaan pembelajaran, serta menumbuhkan budaya literasi dan penilaian hasil pembelajaran. Budaya literasi pada materi sistim periodik unsur mahasiswa

\section{METODE PENELITIAN}

Metode Research and Development (penelitian dan pengembangan) digunakan dalam penelitian ini. Menurut Sugiyono (2015) metode penelitian dan pengembangan dapat diartikan sebagai cara ilmiah untuk meneliti, merancang, memproduksi dan menguji validitas produk yang telah dihasilkan. Penelitian ini mengintegrasikan pengembangan model pembelajaran kimia terintegrasi budaya literasi khususnya pada materi sistem periodik unsur (SPU) mahasiswa semester II S2 Magister Penidikan IPA FKIP UNCEN. Pengembangan menggunakan kelas uji coba skala terbatas dan kelas ujicoba skala luas. Desain adalah OneGroup Pretest-Posttest Design, yang terdiri dari satu kelompok eksperimen tanpa ada kontrol. Desain penelitian ada pada tabel 1 berikut: 
Tabel 1. Desain Penelitian

\begin{tabular}{|c|c|c|c|}
\hline Uji coba & Pelakuan & Pretest & $\begin{array}{c}\text { Post } \\
\text { test }\end{array}$ \\
\hline $\begin{array}{c}\text { Skala } \\
\text { terbatas }\end{array}$ & - & - & - \\
\hline Skala luas & $\mathrm{X}$ & $\mathrm{O}_{1}$ & $\mathrm{O}_{2}$ \\
\hline
\end{tabular}

Keterangan: $\mathrm{X}=$ pembelajaran dengan modul kimia berbasis budaya literasi,

$\mathrm{O}_{1}=$ pretest pada kelas uji coba skala luas, $\mathrm{O}_{2}=$ posttest pada kelas uji coba skala luas

Variabel Penelitian

Variabel bebas dalam penelitian ini adalah pembelajaran dengan menggunakan modul kimia pada materi SPU berbasis budaya literasi Papua,variabel terikat adalah hasil belajar mahasiswa dengan menggunakan modul kimia pada materi SPU berbasis budaya literasi
Papua.Kemudian dilakukan uji validitas dan uji reabilitas menghitung nilai AlphaCronbach untuk reabilitas. Hasil nilai pretest dan posttest sebagai data kuantitatif dianalisis dengan uji n-Gain ternormalisasi (Tabel 2) :

Tabel 2. Nilai rata - rata gain ternormalisasi dan kategorinya

\begin{tabular}{|c|c|}
\hline $\begin{array}{c}\text { Rata }- \text { rata gain } \\
\text { Ternormalisasi }\end{array}$ & Kategori \\
\hline$(\mathrm{g}) \geq 0,70$ & Tinggi \\
\hline $0,30 \leq(\mathrm{g}) \leq 0,70$ & Sedang \\
\hline$(\mathrm{g})<0,30$ & Rendah \\
\hline
\end{tabular}

(Sumber : Elice , 2012)

\section{HASIL DAN PEMBAHASAN}

Hasil validasi validator materi terdapat dalam gambar 1 berikut:

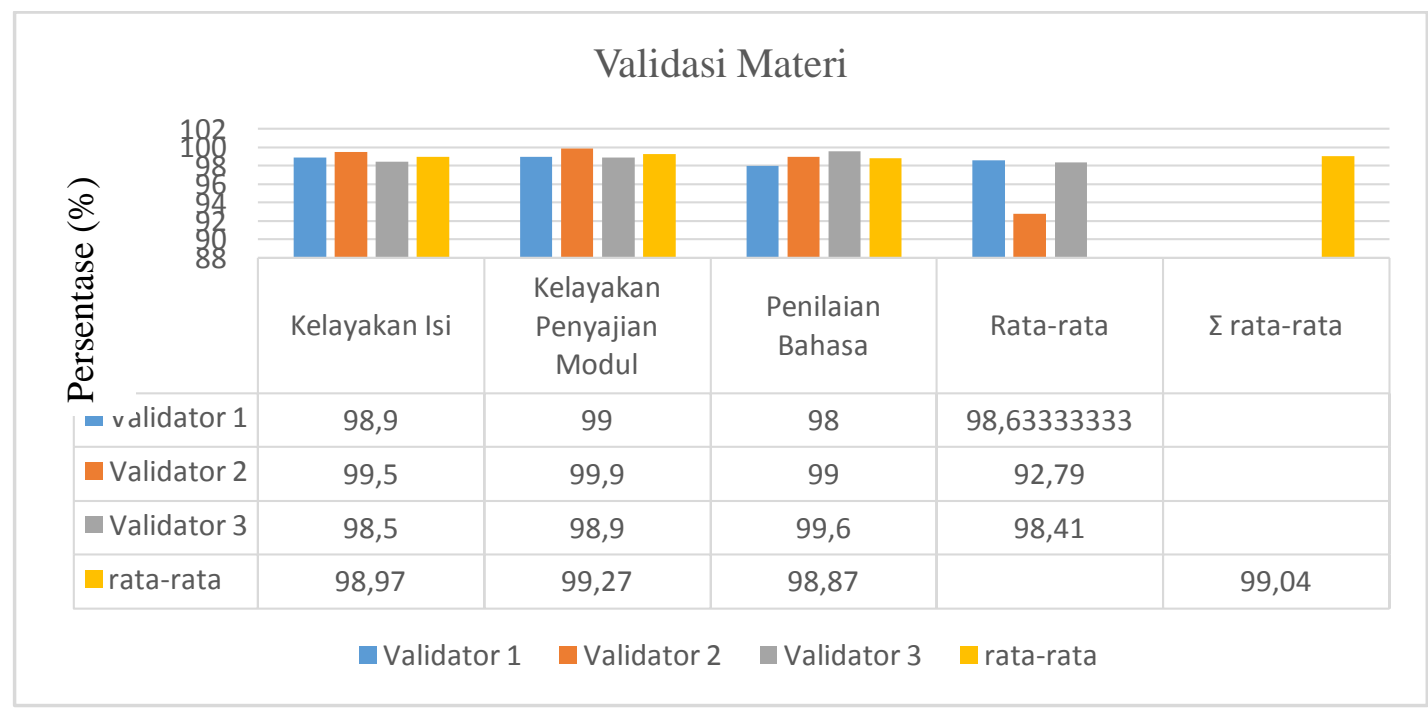

Gambar 1. Diagram Batang Validasi Materi

Gambar 1 diperoleh jumlah skor persentase rata-rata validator 1 sebesar $98,63 \%$, validator 2 sebesar $92,79 \%$ sedangkan validator 3 sebesar $98,41 \%$. Rerata hasil validasi adalah $99,04 \%$ berati hasil validasi ini menunjukan bahwa modul termasuk kategori sangat baik. Hal ini disebabkan konsistensi penggunaan simbol atau lambang unsur,keakuratan tinjauan pustaka, kemenarikan materi, kebakuan istilah, ketepatan penggunaan 
kaidah bahasa dalam modul berbasis budaya literasi Papua.

Angket ujicoba ini diberikan kepada 6 mahasiswa untuk memberikan tanggapan maupun masukan terhadap modul yang ada, kemudian respon dianalisis dengan SPSS 21. Hasil analisis angket respon dengan SPSS 21 tertera pada frekuensi jawaban mahasiswa pada Gambar 2 :

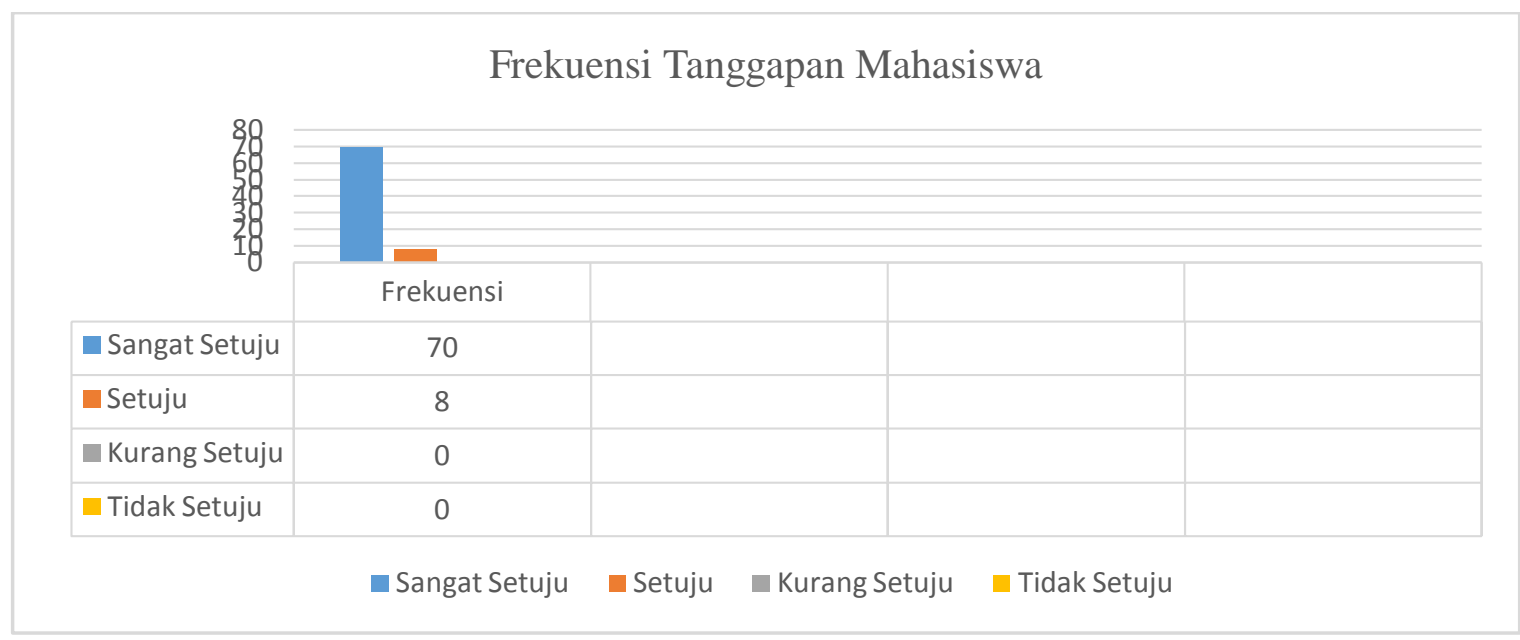

Gambar 2. Diagram Batang Frekuensi Tanggapan Mahasiswa

Berdasarkan Gambar 2, respon mahasiswa terhadap modul frekwensi sangat setuju 70 dan setuju 8 sedangkan kurang setuju dan tidak setuju 0 artinya modul sangat layak digunakan.

Uji validitas dan reliabilitas soal dengan menggunakan SPSS 21 adalah yang valid adalah soal nomor 1,2, 3,6,7, 8,
9 dan 10 sedangkan yang tidak valid adalah soal nomor 4 dan 5 , hanya soal nomor 5 yang tidak reliabel.

Hasil ujicoba skala luas berupa nilai pretest dan post test di analisis dengan nGain yang dilakukan tiga kali pertemuan, ditunjukkan pada Gambar 3:

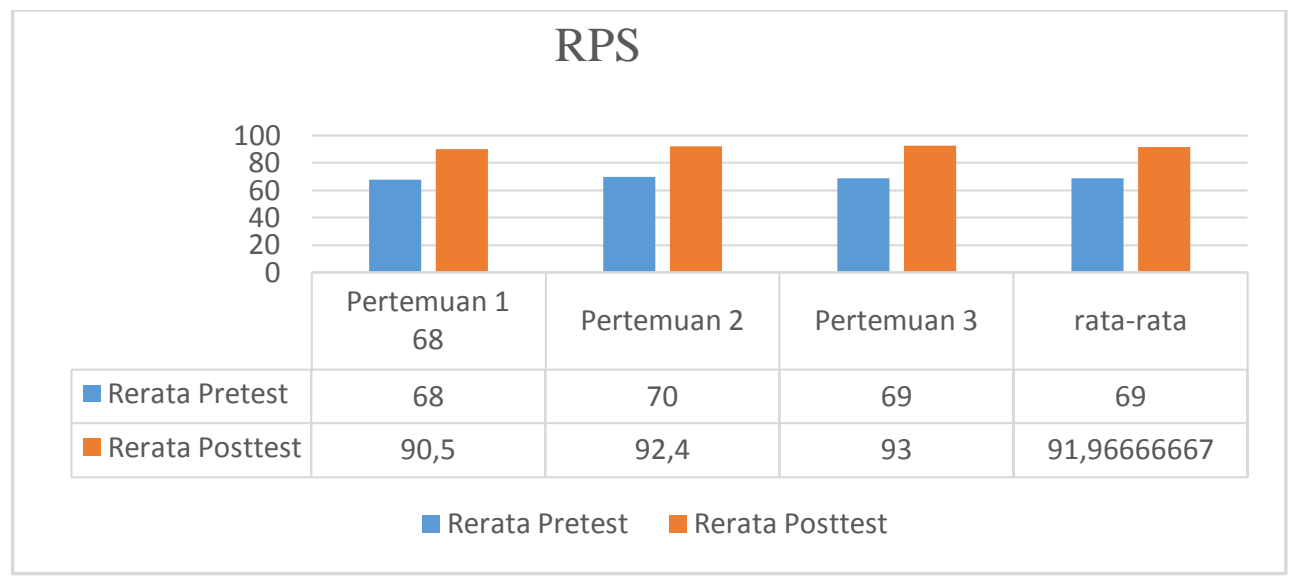

Gambar 3. Diagram Batang Hasil Pembelajaran Tiap Pertemuan

Nilai rata-rata pretes sebanyak tiga kali pertemuan sebesar 69 dan setelah menggunakan modul menjadi 91,97. Hal tersebut membuktikan dengan adanya 
modul kimia berbasis budaya literasi mahasiswa semakin dapat berinteraksi dalam mengetahui simbol atau lambang unsur dan dapat menempatkan periode dan golongan serta mengetahui sifat-sifat dari unsur tersebut dihat dari keperiodikannya. Hal sejalan juga dikemukakan oleh Tiurlina Siregar, Desry Natalia (2019), modul kimia dapat meningkatkan hasil belajar dan juga oleh Sutiani, Silalahi, Situmorang (2017) bahwa model pembelajaran kimia berbasis literasi saintifik dapat meningkatkan kompetensi belajar mahasiswa pada mata kuliah Kimia Fisika. Hasil uji n-Gain selengkapya dapat dilihat pada gambar 4:

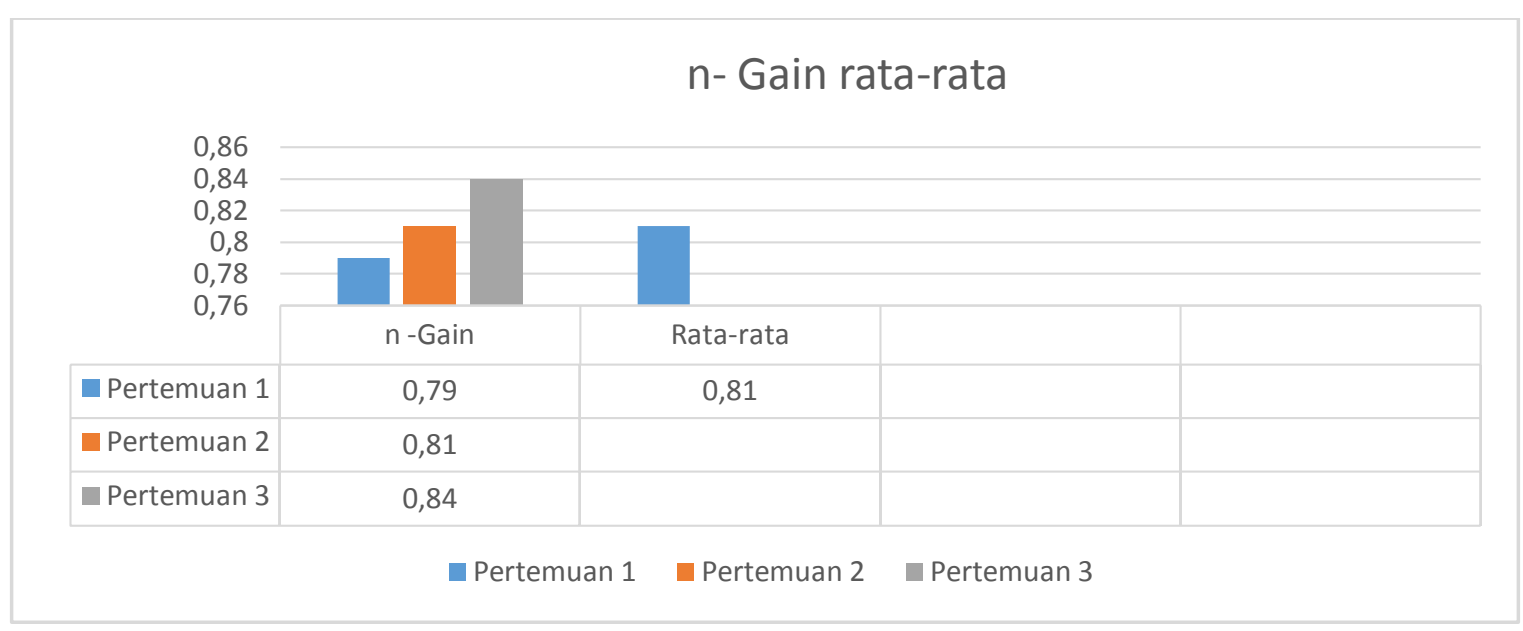

Gambar 4.Diagram Batang n - Gain rata-rata Hasil Belajar Tiap Pertemuan

Berdasarkan Gambar 4, n-Gain ratarata total sebesar 0,81 dengan kategori tinggi yang berarti penguasaan materi SPU dengan modul dapat meningkatkan pemahaman dalam pembelajaran kimia berbasis budaya literatur. Hal ini disebabkan dalam pemberian contoh untuk simbol atau lambang unsur dikaitkan dengan budaya dan kekhasan yang ada di Papua. Hasil penelitian Subiyanto,Tiurlina Siregar (2018), Kearifan lokal Papua dapat meningkatkan hasil belajar kimia. Misalnya: Untuk mempermudah dalam mengingat unsur setiap golongan :

Karbon lambang C digambarkan dengan burung cenderawasih (Gambar 5)
Nitrogen lambang $\mathrm{N}$ digambarkan dengan Noken (Gambar 6):

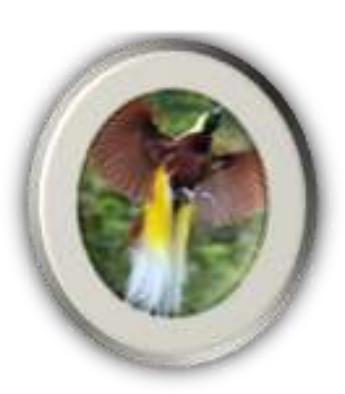

Gambar 5. Lambang Karbon

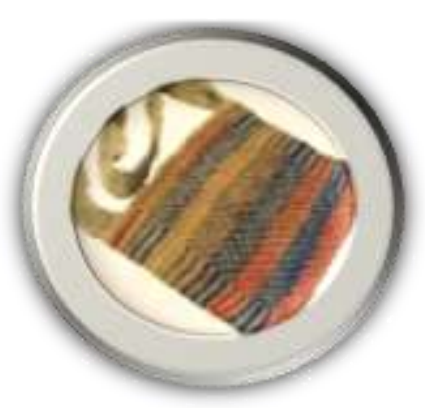

Gambar 6. Lambang Noken

\section{SIMPULAN DAN SARAN \\ SIMPULAN}

Modul pembelajaran kimia pada materi sistem periodik unsur berbasis budaya literasi layak digunakan pada mahasiswa S2 Magister Pendidikan IPA 
FKIP UNCEN. Peningkatan hasil belajar kimia dari tiga kali pertemuan nilai ratarata pretes 69 dan setelah menggunakan modul hasil postes menjadi 91, 97., n-Gain rata-rata sebesar 0,81 dengan kategori tinggi.

\section{SARAN}

Diharapkan dilakukan penelitian pada materi kimia yang berbeda berbasis budaya literasi.

\section{UCAPAN TERIMAKASIH}

Kami mengucapan terimakasih kepada Dekan FKIP UNCEN untuk kerjasamanya dengan program studi S2 Prodi Magister Pendidikan IPA dalam pelaksanaan penelitian ini.

\section{DAFTAR PUSTAKA}

Elice, Deti, 2012, Pengembangan Desain Bahan Ajar Keterampilan Aritmatika Menggunakan Media Sempoa Untuk Guru Sekolah Dasar. Tesis. FKIP Unila PPSJ Teknologi Pendidikan, Bandar Lampung;

Permendikbud Nomor 22, 2016, Standar Proses, Jakarta :Kemendikbud;
Permendibud Nomor 24, 2016, Kompetensi inti dan kompetensi dasar pelajaran Pada kurikulum 201,3 Kemendikbud;

Sugiyono. 2015, Metode penelitian Pendidikan (Pendekatan Kuantitatif, Kualitatif dan $R \& D$ ), Bandung : Alfabeta;

Subiyanto dan Siregar T, 2018, Pengembangan Modul Pembelajaran Kimia Pada Materi Sistem Periodik Unsur Berbasis Kearifan Lokal Papua Peserta Didik Kelas X SMA Negeri 4 Jayapura, Jurnal Ilmu Pendidikan Indonesia, Vol 6 (3) 7182;

Siregar T dan Natalia D, 2019, Modul Pembelajaran Inkuiri Terbimbing Pada Materi Larutan Elektrolit dan Non Elektrolit, Jurnal Ilmu Pendidikan Indonesia, Vol 7 (1) 8 16 ;

Sutiani, A., Silalahi, A. \& Situmorang, M, 2017, The Development of Innovative Learning Material with Problem Based Approach to Improve Students Competence in the teaching pf Physical chemistry, Advances in Social Science, Education and Humanities Research, 104: 378-382. 